\title{
CORRUPÇÃO POLÍTICA: UMA (NOVA) MIRADA À LUZ DA "FACE OCULTA DOS DIREITOS FUNDAMENTAIS" E DO PRINCÍPIO ANTICORRUPÇÃO
}

Graziele Mizumukai Rodrigues ${ }^{1}$

CORRUPCIÓN POLÍTICA: UNA (NUEVA) MIRADA

A LA LUZ DE LA “CARA OCULTA DE LOS DERECHOS

FUNDAMENTALES” Y EL PRINCIPIO ANTICORRUPCIÓN

POLITICAL CORRUPTION: A (NEW) LOOK FROM THE "HIDDEN FACE

OF FUNDAMENTAL RIGHTS”AND THE ANTI-CORRUPTION PRINCIPLE

Fecha de recepción: 17 de agosto del 2020

Fecha de aceptación: 15 de enero del 2021

Disponible en línea: 23 de marzo del 2021

Sugerencia de citación: Mizumukai-Rodrigues, G. (2021). Corrupção política: uma (nova) mirada à luz da "face oculta dos direitos fundamentais" e do princípio anticorrupção. Razón Crítica, (11), 205-228. https:// doi.org/10.21789/25007807.1726

(1) Assessora jurídica da seção de Direito Público do Tribunal de Justiça de São Paulo Doutoranda da Universidad de Buenos Aires, Argentina | grazielemr.doctorado@gmail.com 


\section{R E S U M O}

O presente artigo visa a apresentar a constatação de que a corrupção política se caracteriza como verdadeira violação ao dever fundamental dos agentes políticos de manutenção do pacto social, implicando a ofensa aos direitos fundamentais dos indivíduos que compõem a comunidade política brasileira. A partir desse enfoque e com respaldo no princípio anticorrupção, pode-se conduzir a corrupção política para o nível constitucional, para o âmbito dos deveres fundamentais da pessoa frente à comunidade que compõe o Estado e permite, assim, elevar a responsabilização dos corruptores políticos ao nível de infração de dever fundamental, uma vez que atentam contra a própria estrutura do Estado, enfraquecendo a soberania, violando as instituições democráticas e, em última instância, a dignidade humana.

PALAVRAS-CHAVE: corrupção; deveres fundamentais; infração política; princípio anticorrupção; tutela jurídica do Estado. 


\section{R E S U M E N}

Este artículo pretende demostrar que la corrupción política puede ser considerada como una auténtica violación al deber fundamental de los agentes políticos de proteger el pacto social, lo que implica una ofensa a los derechos fundamentales de los individuos que conforman la comunidad política brasileña. Desde este enfoque, y con el respaldo del principio anticorrupción, la corrupción política puede ser tratada a nivel constitucional — desde los deberes fundamentales de la persona ante la comunidad que compone el Estado-, lo cual permite elevar la responsabilidad de los políticos corruptos al nivel de infracción del deber fundamental, toda vez que estos atentan en contra de la propia estructura del Estado, debilitando la soberanía y vulnerando las instituciones democráticas y, en última instancia, la dignidad humana.

\section{PALABRAS CLAVE: corrupción; deberes fundamentales; infracción política; principio anticorrupción; tutela jurídica del Estado.}

\section{A B S T R A C T}

This article tres to prove that political corruption is characterized as an authentic transgression of the fundamental duties of political agents to protect the social pact, which implies an offense to the fundamental rights of the individuals that comprise the Brazilian political community. From this approach, and backed in the anti-corruption principle, political corruption could be considered as having constitutional status - based on the fundamental duties of a person before the community that constitute the State-, which allows elevating the responsibility of corrupt politicians to a violation of their fundamental duties, considering that they break the very structure of the State, weakening sovereignty and undermining democratic institutions and human dignity.

\section{Keywords: Corruption; fundamental duties; political offense; anti-corruption principle; legal protection by the State.}




\section{N T R O D U Ç Ã O}

O presente artigo decorreu do desenvolvimento de dois trabalhos realizados em paralelo à investigação acerca da corrupção (tema relacionado à minha tese doutoral): "Corrupção: patologia social e alternativas em seu controle" ${ }^{2}$ "O dever fundamental de pagar impostos - contributo para a compreensão constitucional do estado fiscal contemporâneo"3.

Ambos os trabalhos proporcionaram o amadurecimento de questionamentos acerca da corrupção política, abordada num viés mais amplo, com apoio no direito constitucional e nos estudos desenvolvidos por José Casalta Nabais ${ }^{4}$ e Zephyr Rain Teachout ${ }^{5}$.

A tese de Nabais trouxe o debate sobre a "face oculta dos direitos fundamentais", expressão usada em sua tese para se referir aos deveres e aos custos dos referidos direitos, e reavivou a discussão, no cenário acadêmico, dos aspectos não falados dos direitos fundamentais: o contrapeso essencial à sua existência e manutenção dentro do Estado de Direito, os deveres fundamentais — isto é, a responsabilidade de cada indivíduo dentro da estrutura estatal —, essenciais para a manutenção dos direitos fundamentais e, também, para o funcionamento e a própria existência do Estado democrático de Direito.

\footnotetext{
2 Apresentado no IX Congreso Iberoamericano sobre Cooperación Internacional, da Rede Latino-Americana de Juízes (2015), em Valparaíso, Chile, desenvolvido em conjunto com a doutoranda Leilane N. dos Reis Santos.

3 Apresentado no Seminário sobre Fundamentos Constitucionais do Estado, na Faculdade Nacional de Direito da Universidade Federal do Rio de Janeiro (2017), Rio de Janeiro, Brasil.

4 Professor catedrático da Faculdade de Direito da Universidade de Coimbra.

5 Professora associada de Direito da Fordaham University School of Law.
} 
Os conceitos trabalhados em sua tese permitiram a condução à séria reflexão acerca da corrupção política, possibilitando entendê-la muito além da mera transgressão de comportamento ético dos agentes estatais, mas sim como uma verdadeira violação ao dever fundamental de manter o pacto social.

A investigação acerca do tema "corrupção" em seu viés político seguiu aliada ao trabalho desenvolvido por Zephyr Rain Teachout (2009) acerca do princípio anticorrupção como uma decorrência do princípio republicano e de necessário reconhecimento para aprofundar a análise do fenômeno corruptivo e o seu enfrentamento.

A releitura da corrupção a partir desses dois vieses teóricos permite, assim, trazê-la para o nível constitucional, para o âmbito dos deveres fundamentais da pessoa frente à comunidade que compõe o Estado; permite, portanto, elevar a responsabilização dos corruptores políticos ao nível de infração de dever fundamental.

O presente artigo visa a analisar o fenômeno da corrupção, seu impacto na efetivação dos direitos sociais e consequente violação dos direitos fundamentais, além do (re)exame da natureza da conduta corrupta e da correspondente sanção estatal, uma vez que a corrupção política atenta contra a própria estrutura do Estado, enfraquecendo a soberania e provocando a ruína das instituições democráticas - violam, em última instância, a dignidade humana.

\section{"A FACE OCULTA DOS DIREITOS FUNDAMENTAIS" - CONCEITO E FUNDAMENTO JURÍDICO}

Em sua tese intitulada "O dever fundamental de pagar impostos - contributo para a compreensão constitucional do estado fiscal contemporâneo", José Casalta Nabais (2009) desenvolveu importante estudo acerca dos deveres fundamentais e dos custos desses direitos, denominando-os de "a face oculta dos direitos fundamentais", visto que significam a responsabilidade, os deveres e os custos necessários para a materialização desses direitos.

Embora a existência (e a manutenção) dos direitos fundamentais seja condição do constitucionalismo moderno, o estatuto dos deveres fundamentais ainda se encontra oculto nos textos constitucionais, 
passando despercebidamente nos discursos e nas doutrinas que sustentaram a evolução do constitucionalismo.

Todavia, essa "face oculta dos direitos fundamentais" é essencial à manutenção da comunidade política moderna (Estado). E isso porque a transformação do homem em protagonista da nova ordem surgida após o rompimento daquela estabelecida na era medieval, governada pela Lei Divina, levou-o a abandonar o papel de mero beneficiário dessa ordem e erigiu-o a titular de direitos inerentes à sua própria dignidade. Por conseguinte, ao assumir o papel de titular de direitos, passou, também, a deter deveres essenciais à existência e à manutenção da comunidade política a que pertence e está inserido.

A estrutura do Estado moderno alicerçou-se, assim, sobre a dicotomia “direitos-deveres”, ínsita a todos os cidadãos que o compõem. Esses deveres traduzem-se, segundo Soares, em:
deveres de não causar danos a ninguém, de não impedir os outros de se conservarem, de não faltar à palavra dada, de não impedir o outro de enriquecer, deveres comuns ao homem liberal-burguês, ou seja, uma série de orientações em consonância com o contratualismo moderno. Nesse sentido é a existência de um dever de solidariedade e o surgimento da sanção (ou castigo) como um traço identificador dos deveres jurídicos. (2011, p. 196)

Contudo, a influência jusnaturalista alterou a compreensão desse ideal de deveres, que passou a ser compreendido como inerente aos comandos imperativos do legislador nas relações jurídicas ordinárias (decorrentes do direito privado e do direito público - ex vi direito civil, penal) - e afastou-se, assim, do ideal que era visto, e compreendido, em função dos deveres dos cidadãos para com a comunidade a que pertencia. Daí porque a afirmação de Casalta (2007) de que o fundamento jurídico dos deveres fundamentais é a própria Constituição, seja por disposição expressa, seja por implícita, pois, ao partir do princípio da liberdade (ou de sua repartição), o Estado tornou-se responsável pela tutela dos direitos fundamentais e não pode, por decorrência lógica, deixar de impor um dever para a garantia da efetivação desses direitos fundamentais.

Justamente por se tratar de um dever do cidadão para com a manutenção do Estado, seu fundamento decorre da própria Constituição. Por conseguinte, esses deveres constitucionais não necessitam estar 
expressamente consagrados no texto constitucional, podem decorrer implicitamente dos direitos e das garantias fundamentais nele insculpidos.

Os deveres fundamentais, portanto, devem ser compreendidos enquanto categoria jurídica própria, autônoma, e não como uma categoria ético-estatal - isto é, não se devem confundir os deveres fundamentais com uma soma de pressupostos éticos (deveres morais) estabelecidos na Constituição. Afirma Nabais: "os deveres fundamentais constituem uma categoria constitucional própria, expressão imediata ou direta de valores e interesses comunitários diferentes e contrapostos aos valores consubstanciados na figura dos direitos fundamentais" (2007, p. 222).

O professor de Coimbra ressalva, também, que essa categoria jurídico-constitucional não deve ser confundida como limites aos direitos fundamentais ou reflexos dos poderes estatais; os deveres fundamentais são uma categoria constitucional própria colocada ao lado dos direitos fundamentais, ao asseverar que:

os deveres fundamentais constituem uma categoria jurídica constitucional própria. Uma categoria que, apesar disso, integra o domínio ou a matéria dos direitos fundamentais, na medida em que este domínio ou esta matéria polariza todo o estatuto (ativo e passivo), os direitos e os deveres do indivíduo. Indivíduo que não pode deixar de ser entendido como um ser simultaneamente livre e responsável, ou seja, como uma pessoa. Uma idéia que bem precisa ser reforçada na época atual, em que a afirmação do individualismo possessivo, apresentado aliás como um dos apports da pós-modernidade, é cada vez mais onipresente. (Nabais, 2007, p. 15)

Assim, essa "face oculta", embora não seja vista ou falada, compõe o estatuto constitucional do indivíduo; faz-se "absolutamente necessária para a compreensão correta do lugar do indivíduo e, por conseguinte, da pessoa humana em sede dos direitos fundamentais ou dos direitos do homem”, de acordo com Nabais (2017, p. 9). Estão inseridos, portanto, no mesmo plano constitucional dos direitos fundamentais e das liberdades que os concretizam.

O conceito de deveres fundamentais, assim, pode ser erigido a partir de um paralelo com os direitos fundamentais, de modo que é possível apresentar "os deveres fundamentais como posições jurídicas passivas, autônomas, subjetivas, individuais, universais e permanentes e essenciais" (Nabais, 2007, p. 252). 
Diz-se que são posições jurídicas passivas, na medida em que os deveres fundamentais revelam uma situação de dependência dos indivíduos em face do Estado, isto é, o aspecto passivo da relação jurídica estabelecida entre os indivíduos e o Estado, sem, contudo, significar inércia ou inatividade, pois exigem, muitas vezes, atos comissivos ou omissivos de seus titulares. E, justamente, por serem impostas às pessoas são tidas como posição jurídica subjetiva e individual, além de serem consideradas universais e permanentes, porque representam encargos destinados a todos os que compõem a comunidade política, ademais de serem irrenunciáveis. Configuram-se, por fim, como posições jurídicas essenciais, na medida em que são fundamentais para a existência, para o funcionamento e para a subsistência do Estado.

Dessa forma, a tese desenvolvida por Casalta Nabais pôde delimitar materialmente o conceito de deveres fundamentais, de modo a possibilitar a compreensão de que, na "face oculta dos direitos fundamentais", encontram-se os deveres fundamentais ou custos latu sensu dos direitos, que podem ser traduzidos, de acordo com o professor lusitano, na: "responsabilidade comunitária que os indivíduos assumem ao integrar uma comunidade organizada, mormente uma comunidade organizada no estado (moderno), o que faz dos indivíduos verdadeiras pessoas, ou seja, membros ao mesmo tempo livres e responsáveis da sua comunidade" (Nabais, 2007, p. 28).

A partir dessa conceituação e delimitação, chega-se à conclusão de que os deveres fundamentais são essenciais para a manutenção dos direitos fundamentais e, também, para o funcionamento e a própria existência do Estado democrático de Direito. Conclusão essa que nos induz à reflexão acerca da responsabilidade dos indivíduos que assumem o encargo político de gerir o patrimônio e os interesses da comunidade política e desempenham-no de maneira a quebrar a confiança neles depositada pelos seus pares.

O estudo desenvolvido por Casalta Nabais permite trazer à discussão o fenômeno da corrupção política, conduzindo-a para o nível constitucional, para o âmbito dos deveres fundamentais da pessoa frente à comunidade que compõe o Estado, visto que atentam contra sua própria estrutura, enfraquecendo a soberania e provocando a ruína das instituições democráticas. Além disso, impõe-nos a seguinte indagação: a responsabilização desses agentes corruptos deve ser mantida no patamar das infrações legais cometidas pelos indivíduos comuns? 


\section{A CORRUPÇÃO POLÍTICA: VIOLAÇÃO DE UM DEVER FUNDAMENTAL}

Antes de prosseguir com a discussão acerca da responsabilidade dos agentes estatais por atos de corrupção no âmbito político, faz-se importante a delimitação do conceito de corrupção e de seus efeitos para o adequado exame da questão no presente estudo.

\section{Corrupção: conceito e efeitos}

Embora se imponham de primordial relevância a conceituação da corrupção, enquanto objeto deste estudo, assim como o esclarecimento de seu alcance e de seus efeitos, deve-se destacar a impossibilidade de se estabelecer uma abordagem unívoca da corrupção, na medida em que ela se refere a contextos valorativos e sociais que cambiam de acordo com o momento histórico em que analisada.

A definição de corrupção (do latim corruptio) não alcança a conceituação jurídica e sociológica, na medida em que se trata de um fenômeno social, inerente às próprias relações humanas, consistindo no desvirtuamento ou na devassidão de hábitos e costumes através de atos praticados em busca da obtenção de vantagem por meios considerados ilegais ou antiéticos.

O termo "corrupção", então, pode ser adotado para designar um estado ou uma ação que proporciona, nas palavras de Manoel Ferreira Filho, "ora um enfoque dinâmico, ora outro estático” (1991, p. 2), passível de ser visto por diversos ângulos que, por vezes se complementam e por vezes se incompatibilizam, como bem pontuou Virgolini:

esas diversas visiones la han considerado bien un caso arquetípico de conducta desviada en el sentido que desarrolló la sociología de la desviación en el campo de la criminología, bien como un forma de deshonestidad o de inmoralidad individual o grupal, bien como una forma de conducta delictiva típica, o finalmente como un proceso social genérico, ubicuo en el tiempo y en el espacio y por lo tanto ineliminable (sólo pasible de cierta reducción a límites soportables sobre la base de ciertas prescripciones técnicas de orden economicista o de teoría de las organizaciones) etcétera. (2008 p. 83) 
A corrupção, portanto, refere-se à prática de atos desvirtuados que visam à obtenção de vantagens, onde o foco do corruptor repousa na subversão da finalidade estabelecida pelo Direito - desafia a legitimidade racionalmente estabelecida e, assim, subverte a ordem posta através do desrespeito às regras, aos princípios e, também, aos valores tutelados socialmente pelo Direito.

Numa visão ampla do fenômeno, portanto, a corrupção alcança as relações tanto no âmbito público como no privado e mantém relação intrínseca com o elemento confiança, de modo a estabelecer relação inversa entre os níveis de confiança e os índices de corrupção - isto é, nas sociedades em que a confiança entre as pessoas e delas para com o governo é maior, menores os índices de corrupção, assim como naquelas em que os níveis de confiança são menores, maiores os índices de corrupção.

Essa correlação decorre logicamente da própria natureza do ato corruptivo, denotando o enfraquecimento da legitimidade do poder estatal e a erosão da própria democracia com o aumento do desrespeito às regras, aos princípios e aos valores sociais, e, portanto, mais fragilizado Direito posto e a autoridade que dele deveria emanar.

Isso porque, no meio público, a noção de confiança decorre da legitimação do poder resultante do processo constitucionalista de formação dos Estados modernos e da correspondente organização política que limitou os poderes monárquicos, a fim de garantir os direitos da população e a consecução do interesse público, nele incluindo a proteção do patrimônio público confiado à gestão daquele que detém o poder.

Daí porque Filgueiras et al. afirmam que "a corrupção, nessa chave do pensamento político moderno, é quando a passagem do privado ao público ocorre de maneira ilegal. Ou seja, quando o interesse privado se sobrepõe ao interesse público" (2010, p. 321). E justamente neste ponto centra-se o estudo mais restrito do fenômeno: o comportamento do agente público em relação à gestão dos interesses públicos.

A corrupção, então, consoante Pagotto, pode ser conceituada como o: "uso indevido das prerrogativas do Poder Público, por aquele que o detém, para a obtenção de vantagens privadas" (2010, p. 65) — isto é, trata-se de um comportamento estranho à conduta social e que atenta contra a ordem social, que deve ser entendida como o conjunto de valores e sentimentos da maioria da população.

A partir desse conceito, pode-se verificar que o fenômeno corrupção abrange quatro formas clássicas: a social, a econômica, a cultural e a política. E a importância da distinção desses vieses da corrupção justifica- 
se para explicar (e compreender) melhor o alcance desse fenômeno, visto que a subversão dos interesses públicos pelos privados resulta tanto das práticas políticas tipificadas pelo direito posto quanto daquelas que não são consideradas ilegais, mas que são contrárias aos valores e aos princípios adotados pela sociedade.

Tem-se, assim, que a forma mais grave da corrupção advém de seu viés político, caracterizada pela degradação do caráter público dos atos de governo, que acabam por ser "privatizados" para privilegiar os interesses particulares em detrimento do sistema legal estabelecido pelo Estado de Direito. Essa distorção promovida pela corrupção degrada o caráter público dos atos de governo a simples bens de mercado, cujo acesso está determinado pela capacidade econômica dos particulares, além de afetar as relações políticas e sociais regidas pela lei, abalando, portanto, a estrutura do próprio Estado de Direito e da democracia.

O conjunto dessas condutas desviadas conduz, inexoravelmente, ao descrédito da legitimidade estatal pela crise do sistema político e pelo abalo nas relações privadas que, por certo, não só repercutem em aspectos econômicos (público e privado), pois vulneram, sobretudo, o desenvolvimento e a eficiência das atividades estatais destinadas à realização dos direitos sociais e econômicos, mas também ofendem, outrossim, os princípios republicano e democrático sobre os quais se estrutura o Estado brasileiro.

\section{O princípio republicano e o princípio anticorrupção na Constituição brasileira de 1988}

A Constituição brasileira de 1988 (CF/88) foi inaugurada em seu Título I com os princípios que fundamentam o Estado brasileiro. Logo de seu artigo $1^{\circ}$, extrai-se o princípio republicano que permeia toda a estrutura do pacto social firmado, além de ter estabelecido o princípio democrático como sua base constitutiva e a forma como deve ser efetivado:

Art. $1^{\circ}$ A República Federativa do Brasil, formada pela união indissolúvel dos Estados e Municípios e do Distrito Federal, constituise em Estado Democrático de Direito e tem como fundamentos:

I - a soberania;

II - a cidadania

III a dignidade da pessoa humana;

IV - os valores sociais do trabalho e da livre iniciativa;

$\mathrm{V}$ - o pluralismo político. 
Parágrafo único. Todo o poder emana do povo, que o exerce por meio de representantes eleitos ou diretamente, nos termos desta Constituição. (CF/88, art. $1^{\circ}$ )

Estabeleceu, ainda, os demais elementos estruturantes do pacto social e político ao afirmar o poder do povo e a estruturação do Estado com base na separação de poderes, além de afirmar o objetivo de construir uma sociedade livre, justa e solidária, e garantir o desenvolvimento nacional, erradicar a pobreza e a marginalização, reduzir as desigualdades sociais e regionais, e promover o bem de todos, consoante se extrai dos artigos $2^{\text {o6 }} \mathrm{e}$ $3^{07}$ da Carta Política brasileira.

Trata-se de princípios de observância inexorável para a interpretação de todo o texto constitucional e a legislação ordinária nacional, de modo que os demais princípios contidos na Carta política brasileira, sejam eles explícitos, sejam implícitos, devem ser lidos e interpretados em conjunto, por representarem os valores adotados pelo Poder Constituinte ao inaugurar a Carta Política do Estado brasileiro em 1988. Daí se extrai a conclusão de que todo comportamento dos agentes estatais, sejam servidores, agentes públicos ou agentes políticos, deve pautar-se pela principiologia do Título I da Constituição republicana de 1988.

O exercício simples de lógica demonstra que o descumprimento do dever de agir em conformidade com as regras e os princípios estabelecidos inviabiliza a consecução desses objetivos tidos por fundamentais.

Assim, justamente por visar à tutela dos objetivos e dos direitos fundamentais, a par do princípio republicano e democrático, a Constituição da República edificou a estrutura estatal sobre os pilares dos princípios da moralidade, da impessoalidade e da legalidade impostos à Administração Pública, e explicitou o dever de probidade aos agentes públicos e políticos em seu artigo $37^{8}$, no caput e no parágrafo $4^{\circ}$, da CF/88.

\footnotetext{
$6 \mathrm{CF} / 88$, Art. $2^{\circ}$ - São Poderes da União, independentes e harmônicos entre si, o Legislativo, o Executivo e o Judiciário.

$7 \mathrm{CF} / 88$, Art. $3^{\circ}$ - Constituem objetivos fundamentais da República Federativa do Brasil: I - construir uma sociedade livre, justa e solidária; II - garantir o desenvolvimento nacional; III - erradicar a pobreza e a marginalização e reduzir as desigualdades sociais e regionais; IV promover o bem de todos, sem preconceitos de origem, raça, sexo, cor, idade e quaisquer outras formas de discriminação.

8 CF/88, Art. 37 - A administração pública direta e indireta de qualquer dos Poderes da União, dos Estados, do Distrito Federal e dos Municípios obedecerá aos princípios de legalidade, impessoalidade, moralidade, publicidade e eficiência e, também, ao seguinte: [...] $\S 4^{\circ}$ - Os atos de improbidade administrativa importarão a suspensão dos direitos políticos, a perda da função
} 
Do exame da principiologia estabelecida no corpo constitucional, extrai-se, assim, o propósito (constitucional) do modelo republicano eleito em 1988, qual seja o de edificar um Estado probo, transparente em suas relações e voltado para tutelar o interesse público, entendido em seu aspecto mais amplo — isto é, avesso à corrupção. Pode-se, então, afirmar que daí se extrai outro princípio basilar: o princípio anticorrupção.

Nas palavras de Carneiro Júnior:

Uma análise textual incidente sobre a forma de organização política, social e administrativa, ou seja, a estrutura institucional do Estado, indica a adoção de princípios expressos e implícitos na Constituição brasileira. Mais do que sugerir, faz constatar a existência de um forte enleio dessas cláusulas específicas e o propósito para a qual a Constituição foi projetada. A Constituição estabelece cláusulas constitucionais específicas que delineiam o modelo de República almejado. Tais cláusulas vinculam-se a esse standard a ponto e lastrear uma premissa maior anticorrupção: um princípio geral independente que se encontra no mesmo nível do Princípio da Tripartição das Funções de Poder e do próprio Princípio Republicano, por exemplo, aos quais estão umbilicalmente afetados todos os demais princípios, bem como direitos e garantias fundamentais. (2015, pp. 36-37)

Para Zephyr Rain Teachout (2009), o princípio anticorrupção decorre do princípio republicano e, portanto, seu reconhecimento como princípio estruturante é necessário para aprofundar a análise do fenômeno corruptivo e possibilitar o seu enfrentamento a partir de uma abordagem teleológica ancorada no propósito constitucional.

A busca pelo propósito constitucional torna, portanto, imprescindível a harmonização de todos os princípios reunidos na Constituição para estruturar o Estado brasileiro. Desta maneira, impossível ocultar a existência do princípio anticorrupção e, sobretudo, o lugar de destaque que ocupa: o de princípio nuclear para o alcance e a manutenção de seu propósito constitucional. O princípio anticorrupção, assim, enquanto princípio nuclear, deve servir de conduto interpretativo de todo o texto constitucional e das normas infraconstitucionais. 
Nesse sentido, em razão da semelhante organização principiológica republicana estadunidense com a Constituição brasileira, podem ser acolhidas as palavras de Zephyr Teachout que, ao se referir à Constituição dos Estados Unidos da América, afirmou:

I argue that the anti-corruption principle should have legal weight because courts should take into account general purposes of the U.S. Constitution when deciding particular cases that involve particular clauses. We will call this theory "constitutional purposivism".

Purposivism is a judicial and scholarly approach that "inquir[es] into legislative or regulatory purpose"9. (2014, p. 2)

O princípio anticorrupção, ainda que implícito na Carta política de 1988, consiste em um desdobramento direto e imediato do processo constitucionalista do qual decorreu a organização do Estado brasileiro calcado na democracia e nos limites estabelecidos pela norma fundamental. Ele pode ser visualizado tanto a partir dos propósitos constitucionais quanto da estrutura que o alicerça, de modo a orientar e ditar suas atividades e a interpretação de todas suas normas (constitucionais e infraconstitucionais).

\section{A necessidade de adoção do enfoque de Direitos Fundamentais ao fenômeno corrupção}

Independentemente da forma expressada pela corrupção, isto é, da forma como ela é praticada, inegavelmente se confluirá para o mau desempenho das funções e das tarefas públicas (sejam efeitos diretos, sejam indiretos da prática corruptiva), o que, por consequência, implica a violação dos direitos fundamentais, na medida em que, tanto o abuso da força quanto a negligência ou a ineficiência na prestação de serviços públicos à população, refletem a ausência de cumprimento adequado dos deveres estatais e redundam em prejuízos à realização dos direitos fundamentais, tanto os individuais como os sociais - protegidos no plano interno e externo, internacionalmente.

9 "Eu defendo que o princípio anticorrupção deve ter peso legal porque os tribunais devem levar em consideração os objetivos gerais da Constituição dos EUA ao decidir casos específicos que envolvem cláusulas específicas. Chamaremos essa teoria de 'propósito constitucional'. O propósito é uma abordagem judicial e acadêmica que 'investigações sobre o propósito legislativo ou regulatório"” (Teachout, 2014, p. 2; tradução livre). 
Isso porque, de acordo com o Pacto Internacional dos Direitos Econômicos, Sociais e Culturais, que prevê a proteção de uma extensa gama de direitos do homem, os Estados devem comprometer-se na implementação progressiva desses direitos sociais. Segundo Piovesan:

Se os direitos civis e políticos devem ser assegurados de plano pelo Estado, sem escusa ou demora — têm a chamada autoaplicabilidade —, os direitos sociais, econômicos e culturais, por sua vez, nos termos em que estão concebidos pelo Pacto, apresentam realização progressiva. Vale dizer, são direitos que estão condicionados à atuação do Estado, que deve adotar todas as medidas, tanto por esforço próprio como pela assistência e cooperação internacionais, principalmente nos planos econômicos e técnicos, até o máximo de seus recursos disponíveis, com vistas a alcançar progressivamente a completa realização desses direitos (artigo $2^{\circ}$, parágrafo $1^{\circ}$ do Pacto) (2011, p. 213).

A observância da ética na conduta dos agentes públicos, especialmente no tocante ao "dever-ser" sobre instituições e políticas públicas, tem especial importância na prevenção e no combate de condutas lesivas à efetivação dos direitos sociais das pessoas humanas.

Daí a necessidade do enfoque dos Direitos Fundamentais sobre o assunto, despertando a atenção da sociedade acerca da importância do tema, haja vista que são as pessoas que a compõem que são postas em situação de verdadeira vulnerabilidade perante os agentes públicos e particulares corruptos ao terem seus direitos individuais e sociais violados pelo manejo inadequado dos instrumentos de poder (político e econômico).

Ademais, os direitos humanos reconhecidos interna e externamente (por meio de diplomas nacionais e internacionais) impõem obrigações aos Estados, de modo a legitimar seus sujeitos de direito a protestar contra atos de corrupção e a exigir proteção quanto aos prejuízos sofridos por causa desses atos.

Pode-se, então, concluir que, além de atribuírem legitimidade às pessoas submetidas a atos de corrupção, os direitos humanos orientam os Estados no cumprimento de seus deveres e obrigações para que cumpram suas responsabilidades em matéria de direitos humanos em todos os níveis. Assim, a partir dessa perspectiva da inter-relação dos atos de corrupção com as violações dos direitos humanos, permite-se a criação de novas possibilidades para sua prevenção e em seu combate, notadamente, se 
vistos à luz do princípio anticorrupção decorrente do próprio processo constitucionalista.

\section{Corrupção e violação dos direitos fundamentais}

O segundo ponto de abordagem indispensável reside na forma como os atos de corrupção violam os direitos fundamentais. Importante, assim, assentar a dinâmica básica que fundamenta a corrupção — isto é, a compreensão de que os agentes corruptos buscarão sempre a manutenção de seu status quo visando à manutenção de seu poder e à obtenção de vantagens, geralmente financeiras, às custas da opressão dos direitos daqueles que não estão no poder. E, nesta opressão de direitos, inclui-se a maioria das pessoas que pertencem aos grupos vulneráveis, ou seja, aquelas pessoas que dependem da atuação estatal para alcançarem seus direitos fundamentais mínimos.

Importante, também, o esclarecimento de que as obrigações do Estado quanto aos direitos fundamentais compreendem, em resumo, a obrigação de respeito, a obrigação de proteção e a obrigação de garantia - as quais foram assim definidas por Alessandra Quines Cruz:

a obrigação de respeito inclui a noção de que o Estado deve se abster de tomar qualquer atitude que prive o indivíduo do gozo de seus direitos, o que é geralmente associado aos direitos civis e políticos (como, por exemplo, na obrigação de não torturar), mas também pode ser vista sob o enfoque dos direitos econômicos, sociais e culturais. A obrigação de proteção, por sua vez, exige que o Estado previna violações de terceiros, enquanto a obrigação de garantia inclui a noção de que o Estado deve tomar medidas para que os indivíduos sob sua proteção possam satisfazer suas necessidades básicas. (2014, pp. 6-7)

Partindo dessas premissas, torna-se fácil a compreensão de que a corrupção viola os direitos fundamentais de forma direta ao impedir a concretização de obrigações estatais como a educação e a saúde para as pessoas, por exemplo, obrigando-as a arcarem pessoalmente com esses custos.

Ofende-os, também, de forma indireta, na medida em que a corrupção passa a ser um fator essencial para a violação dos direitos fundamentais, como, por exemplo, no caso em que funcionários públicos permitem a circulação de mercadorias e produtos que não preenchem os requisitos legais de segurança para a vida e a saúde das pessoas - 
afrontando, assim, a garantia fundamental do direito à vida e à saúde, insculpidos no caput dos artigos $5^{\mathrm{o} 10}$ e $6^{\mathrm{ol1}}$ da Constituição da República brasileira de 1988.

Desta feita, tem-se por imperiosa a importância da consciência sobre a relação de causalidade entre corrupção e violação dos direitos fundamentais, para que se possa atribuir à corrupção o peso jurídico adequado aos efeitos nefastos que ela produz no âmbito dos direitos fundamentais, albergando em sua "face oculta" o descumprimento do dever estatal de garantir a tutela e a efetivação dos direitos fundamentais das pessoas que compõem a comunidade política. Somente com o posicionamento da corrupção política no plano constitucional poder-se-á atribuir-lhe a responsabilidade adequada e, por conseguinte, fortalecer a democracia e prevenir efeitos nefastos desses atos para a manutenção do Estado de Direito.

\section{Corrupção: uma violação ao pacto social}

Por se referir à prática de atos desvirtuados que visam à obtenção de vantagens, a corrupção subverte a finalidade estabelecida pelo Direito, além de desafiar a legitimidade do poder racionalmente estabelecida ao desrespeitar as regras, os princípios e, também, os valores tutelados socialmente pelo Direito.

Como já assentado, no meio público, a noção de confiança decorre da legitimação do poder resultante do processo constitucionalista de formação dos Estados modernos e da correspondente organização política que limitou os poderes monárquicos, a fim de garantir direitos da população.

A legitimidade do poder implica, para o agente político, o dever de observância da coerência entre a conduta e a consecução do interesse público, nele incluindo a proteção do patrimônio público confiado à gestão daquele que detém o poder para a consecução das políticas públicas destinadas à promoção do bem-estar social. O desrespeito a esse dever implica o aumento da desconfiança na guarda do interesse público e provoca deterioração na própria legitimidade do poder, na medida em que 
ocorre uma traição à confiança neles depositada. Sob esse enfoque, há, em verdade, uma verdadeira violação ao contrato social.

$\mathrm{E}$ isso porque o pacto social fundamenta uma igualdade moral $\mathrm{e}$ legítima, substituindo uma desigualdade física entre os homens, de forma que todos os homens se tornam iguais por convenção e direito. Pode-se, assim, asseverar que o contrato social se traduz numa forma de associação cujo fim é proteger e defender a pessoa, seus bens e interesses dentro dessa comunidade política. Para isso, o homem despe-se de sua liberdade natural em detrimento da liberdade civil, que passa a ser guiada por normas e leis de convívio social e sob o comando de agentes escolhidos para a gestão do bem público, comum. Os homens, no contrato social, cedem espaço para a justiça e a moralidade, dentro de limites da vontade geral - a qual somente o Estado poderá dirigir, já que, se não houver um ponto comum de interesse, nenhuma sociedade poderá existir.

A soberania, portanto, pode ser sintetizada como o exercício da vontade geral, que propende para a igualdade, a qual, para existir, necessita de convenções e leis para unir os direitos aos deveres e conduzir a justiça a seu fim.

Portanto, a corrupção política viola não só a confiança depositada nos agentes políticos eleitos pela maioria. Essa violação vai mais além: alcança a higidez do pacto social e provoca a ruptura a estrutura do Estado democrático e de Direito. Nesse sentido, assevera Armando Rafael Aquino Brito:

El funcionario no solo viola la ley, sino el contrato social basado en la confianza que se expresa a través del sufragio, no tiene imperativa ni coactivamente impuesta una actividad o función sino que voluntariamente se somete a ella. Desde ese lugar violenta el mandatoconfianza, también irradia un disvalor impropio de los principios y mandatos del texto constitucional. (Brito, 2016, p. 3)

O conjunto dessas condutas políticas desviadas, assim, conduz, inexoravelmente, ao descrédito da legitimidade estatal pela crise do sistema político e pelo abalo nas relações privadas que, por certo, repercutem no desenvolvimento e na manutenção da comunidade política fundada na democracia e no Direito. 


\section{CORRUPÇÃO POLÍTICA: AMEAÇA À \\ MANUTENÇÃO DO ESTADO DEMOCRÁTICO \\ DE DIREITO BRASILEIRO - OFENSA \\ AO PRINCÍPIO DA ANTICORRUPÇÃO E VIOLAÇÃO DE UM DEVER FUNDAMENTAL}

Feita a delimitação do conceito de corrupção e de seus efeitos, volta-se o presente estudo para o exame acerca da responsabilidade dos agentes estatais por atos de corrupção no âmbito político a partir da delimitação material do conceito de deveres fundamentais.

Como já assentado, os deveres fundamentais (ou custos lato sensu dos direitos) nada mais são do que a responsabilidade comunitária dos indivíduos ao aderirem ao pacto social, porquanto, nessa noção de responsabilidade coletiva de cada qual para com o Estado, repousa o equilíbrio para a manutenção dos direitos fundamentais.

Por sua vez, essa relação subjetiva e autônoma dos indivíduos perante o Estado é, também, essencial para o funcionamento e para a própria existência do Estado democrático de Direito.

Diante desse vínculo estabelecido entre os indivíduos e o Estado, com obrigações recíprocas, extrai-se o dever imposto aos agentes políticos ${ }^{12} \mathrm{de}$ agir em conformidade com as regras e os princípios estabelecidos pelo Estado, a fim de gerir unicamente o interesse público para a manutenção da democracia firmada com o contrato social.

Como já assentado, o descumprimento desse dever implica, assim, a quebra da confiança nos agentes políticos depositada pela coletividade, além de desrespeitar princípios fundamentais insculpidos no texto constitucional de 1988, notadamente os reunidos em seu Título I ("Dos Princípios Fundamentais”). Implica, ainda, reitera-se, a ofensa direta aos elementos estruturantes do pacto social e político brasileiro, inviabilizando a consecução dos objetivos tidos por fundamentais — isto é, vulnera os princípios republicano e democrático que norteiam o arcabouço normativo e valorativo do Estado brasileiro.

12 Agentes políticos, aqui, devem ser entendidos como aqueles que voluntariamente se dispuseram a ocupar cargos e funções destinadas à gestão do interesse dos membros de uma comunidade política, aqueles a quem a coletividade depositou a confiança para gerir seus interesses, tutelar seus direitos e garantias fundamentais. 
A ofensa, portanto, à forma como se estruturou a comunidade política brasileira — num Estado democrático e de Direito - implica violação ao acordo primeiro firmado pelo Poder Constituinte Originário, uma verdadeira afronta ao pacto social. Segundo defende Pagotto, em sua tese doutoral:

\begin{abstract}
Muito mais do que mera quebra de formalidade ínsita ao Estado moderno, a corrupção possui efeitos deletérios sobre o tecido social, contaminando a política e a economia. Em razão desses efeitos, justifica-se a preocupação estatal na tomada de ações para combater a corrupção. Para evitar que as conclusões sejam por demais niilistas e resvalem num moralismo até mesmo midiático ou apontem para uma suposta equivocada deformação atávica da formação social do povo brasileiro, é necessário reafirmar a legitimidade do combate à corrupção enquanto parte da ação estatal. (2010, p. 30)
\end{abstract}

Daí emergir a conclusão de que a responsabilidade dos indivíduos que assumem o encargo político de gerir o patrimônio e os interesses da comunidade política, e desempenham-no de maneira a quebrar a confiança neles depositada pelos seus pares, está fundada primeiramente na própria Constituição da República, por se traduzir no descumprimento de um dever fundamental que decorre diretamente do artigo $1^{\circ} \mathrm{da} \mathrm{CF} / 88$, qual seja, o dever de manter a estrutura do Estado, a soberania e as instituições democráticas.

Vista por esse enfoque constitucional, a corrupção política enquanto ofensa a um dever fundamental implícito deve, por decorrência lógica, ser vista como uma conduta de caráter especial, destacada das demais modalidades de corrupção tipificadas na legislação penal e administrativa.

Armando Rafael Britos, em seu trabalho acerca da corrupção, impôs o seguinte questionamento: “¿La violación al contrato social —constitución - tiene un carácter especial? o ¿sus violadores están amparados por las garantías típicas y normales previstas en el ordenamiento ordinario?" (Britos, 2016, p. 3).

Assim, à luz do princípio anticorrupção, decorrente, sobretudo, do princípio republicano e da legitimidade político-democrática, consoante defendido por Zephyr Rain Teachout (2009), é possível trazer a prática da corrupção em seu viés político para o nível constitucional, para o âmbito dos deveres fundamentais da pessoa frente à comunidade que compõe o Estado. Isto é, permite-se, assim, elevar a responsabilização dos 
corruptores políticos ao nível de infração de dever fundamental e, por conseguinte, possibilita a revisão da natureza da conduta do corruptor político e a adequação da sanção estatal, tornando-a mais adequada à gravidade das consequências causadas pela violação ao pacto social, visto que a incorreta e a insuficiente repreensão à corrupção política atenta contra a própria estrutura do Estado, enfraquecendo a soberania e provocando a ruína das instituições democráticas - viola, em última instância, a dignidade humana.

\section{CONGLUSÕES}

Embora sabidamente impossível esgotar o debate acerca do preocupante tema da corrupção política nessas breves linhas, o intuito deste artigo foi destacar a importância da repercussão do tema para os Direitos Fundamentais e para a manutenção do Estado democrático, especialmente no que tange à proteção destinada a combater a violação dos referidos direitos, bem como trazer à reflexão do assunto à luz dos deveres fundamentais decorrentes do pacto social.

A evidente relação entre a efetivação dos direitos sociais e a corrupção desperta a atenção para a necessidade de aperfeiçoar os mecanismos de análise e de repressão dos atos de corrupção e para que possa, assim, permitir ao sistema jurídico a adoção de instrumentos mais adequados para combater de modo eficaz essa prática que assola o interesse público e possibilitar a efetivação mais ampla dos direitos sociais. Assim, nas palavras de Flavia Piovesan,
se os direitos humanos não são um dado, mas um construído, as violações a estes direitos também o são. As violações, as exclusões, as injustiças são um construído histórico a ser desconstruído. É emergencial assumir o risco de romper com uma cultura que trivializa, naturaliza e banaliza a desigualdade e a exclusão social. (2011, p. 225)

Apesar de não se ter esgotado o exame da corrupção política como uma violação ao dever fundamental de manutenção da democracia e do Estado de Direito expressamente firmado na Constituição da República de 1988, restou clara sua influência negativa sobre a efetivação e a proteção dos direitos fundamentais, no desequilíbrio da democracia brasileira, na ofensa ao princípio anticorrupção, haja vista que a corrupção é uma das 
causas concretas das desigualdades sociais e da ausência de prestações públicas de atendimento à saúde, à educação, ao desenvolvimento econômico e social.

Demonstrou-se, assim, a necessidade de elevar também as políticas públicas de combate ao fenômeno corruptivo ao plano constitucional, na importância da atuação pública e da observância ao princípio anticorrupção, a fim de promover a efetivação dos princípios e dos fundamentos firmados pelo Constituinte de 1988, e, ainda, efetivar a soberania também no plano internacional por meio do cumprimento das proteções globais estabelecidas pela Convenção das Nações Unidas contra a Corrupção e os programas do Escritório das Nações Unidas sobre Drogas e Crime no sistema global de proteção dos direitos humanos.

Com relação à punição dos envolvidos em práticas corruptas, a gravidade das consequências das condutas corruptas sobre a coletividade a par da insuficiência dos atuais instrumentos penais e administrativos para o seu combate denunciam a necessidade de adequação, e talvez ampliação, dos instrumentos estatais para promover a tutela dos direitos fundamentais - o que, sem dúvida, pode ser feito a partir da elevação da corrupção ao patamar de violação a um dever fundamental contido no plano constitucional.

A adequação da repreensão (e efetiva punição) à corrupção política, enquanto violação do pacto social, deve ser repensada, não sem antes elevá-la ao patamar constitucional, destacando-a da política criminal já estabelecida para as infrações ordinárias, de modo a reconhecer seu caráter especial. Isso possibilitaria o ajuste das garantias processuais e materiais para os agentes políticos corruptores, retirando-os do plano de garantias típicas e normais previstas no ordenamento jurídico ordinário.

Seguindo essa linha argumentativa, assevera Almicar Araújo Carneiro Júnior:

Face à situação atual, há necessidade de um renascimento, um revival, um autêntico reflorescimento de uma República que incorpore na prática tudo aquilo que já se encontra previsto na Constituição brasileira, documento fundamental e que estabelece linhas mestras no âmago de uma arquitetura de combate à corrupção. Por isso, há de se reconhecer a existência de um veraz princípio anticorrupção de caráter geral, implícito na Constituição brasileira, visualizado tanto a partir de seus propósitos quanto a partir da estrutura que a alicerça, bem como "bem como os argumentos sobre o que constituições em geral 
são projetadas para fazer", de modo a nortear e ditar as atividades e a interpretação do Direito por parte de todos os Poderes da República. Não é o caso somente da atuação de um sistema repressivo, no que tange à aplicação de reprimendas aos agentes públicos e privados, após apuração de condutas ilícitas, recebimento de propinas e vantagens pessoais e para terceiros em prejuízo do patrimônio público e dos mais lídimos interesses do bem comum. (Carneiro Júnior, 2015, p. 38)

Os conceitos e os efeitos do fenômeno apresentados neste trabalho visaram a uma abordagem mais ampla da questão e a destacar a importância da revisão da corrupção em seu viés político a partir do conceito de deveres fundamentais inserido no plano constitucional e presente na Constituição brasileira de 1988.

O apoio teórico desses conceitos ao trabalho desenvolvido por Zephyr Rain Teachout e José Casalta Nabais possibilita a releitura da corrupção, notadamente a política, trazendo-a para o nível constitucional, para o âmbito dos deveres fundamentais. Assim, permite-se elevar a responsabilização dos corruptores políticos ao nível de infração de dever fundamental, além de abrir espaço, outrossim, para a readequação das sanções e das políticas públicas voltadas à recuperação da dignidade humana e coletiva, e da integridade das instituições democráticas no Estado brasileiro.

\section{REFERÊNGIAS}

Assembleia Nacional Constituinte do Brasil (1988). Constituição da República Federativa do Brasil de 1988. http://www.planalto.gov.br/ccivil_03/ Constituicao/ConstituicaoCompilado.htm

Britos, A. R. A. (2016). Traición a la patria y corrupción. Garantía constitucional y la necesidad de su instrumentación. Revista de Derecho Penal y Criminología, 5, 89-106.

Carneiro-Júnior, A. A. (2015, setembro). A República brasileira e o princípio constitucional anticorrupção. Anais do Programa de doutoramento em Direito, justiça e Cidadania no Século XXI. Faculdades de Direito e Economia da Universidade de Coimbra. Coimbra, Portugal.

Cruz, A. Q. (2014). A luta contra a corrupção sob um enfoque de direitos humanos e as possibilidades de atuação da defensoria pública. Associação Nacional de Defensoras e Defensores Públicos. https://anadep.org.br/wtk/pagina/ materia?id=20670 
Ferreira-Filho, M. G. (1991). A corrupção como fenômeno social e político. Revista de Direito Administrativo, 185, 1-18. https://doi.org/10.12660/rda. v185.1991.44482

Filgueiras, F., Montandon, A. M., Oliveira, B. M. A., \& Abreu, I. M. (2010). Corrupção, cultura política e reformas no Brasil. Revista de C. Humanas, 10(2), 318-334. https://periodicos.ufv.br/ $\mathrm{RCH} /$ article/view/3485

Nabais, J. C. (2002). A face oculta dos direitos fundamentais: os deveres e os custos dos direitos. Revista Direito Mackenzie, 3(2), 9-30. http://editorarevistas. mackenzie.br/index.php/rmd/article/view/7246

Nabais, J. C. (2007). Por uma liberdade com responsabilidade: estudo sobre os direitos e deveres fundamentais. Coimbra Editora.

Nabais, J. C. (2009). O dever fundamental de pagar impostos. Contributo para a compreensão constitucional do estado fiscal contemporâneo. Editora Almedina.

Pagotto, L. U. C. (2010). O combate à corrupção: a contribuição do Direito Econômico [tese de doutorado, Faculdade de Direito da Universidade de São Paulo]. https://www.teses.usp.br/teses/disponiveis/2/2133/tde-21112011-103454/ptbr.php

Piovesan, F. (2011). Proteção dos direitos sociais: desafios do ius commune sulamericano. Revista de Estudos Constitucionais, Hermenêutica e Teoria do Direito (RECHTD), 3(2), 206-226. https://doi.org/10.4013/rechtd.2011.32.09

Soares, H. C. (2011). As políticas públicas e o objeto da relação tributária: da existência do dever de pagar impostos e de quando direitos não nascem em árvores. Revista Jurídica Orbi, 2(2).

Teachout, Z. R. (2009). The anti-corruption principle. Cornell Law Review, 94(341), 342-413. https://scholarship.law.cornell.edu/cgi/viewcontent. cgi? article $=3123 \&$ context $=$ clr

Teachout, Z. R. (2014). Constitutional purpose and the anti-corruption principle. Northwestern University Law Review Online, 108, 200-217. https:// scholarlycommons.law.northwestern.edu/nulr_online/24/

Virgolini, J. E. S. (2008). Crimenes excelentes. Delitos de cuello blanco, crimen organizado y corrupción. Editores del Puerto. 